\title{
A Current State Performance Framework for the Evaluation of User Experience Design (UXD) Practice in Industry
}

\author{
Idyawati Hussein, Azham Hussain, Emmanuel O.C. Mkpojiogu, ChenKim Lim, KiamLam Tan
}

\begin{abstract}
This study proposes a current state analysis framework for the understanding and evaluation of the user experience design (UXD) practice in industry.In this study, using $P A R$ and grounded theory, an evaluation framework was developed to assess the UXD practice in industry. The study was conducted among a UXD community of practice, UX Malaysia. The proposed framework incorporated implicit, and explicit design practices as well as practice constraints. Implicit practice is grouped into values and goals while explicit practice comprises of job roles/design decision and knowledge. Constraints encountered by individuals who are motivated to practise user experience design in the development process include those related to: direct control, between direct control and indirect control, indirect control, between indirect control and no control and no control.
\end{abstract}

Keywords: Community of practice, current state analysis framework, user experience design practice

\section{INTRODUCTION}

Wenger et al., (2011) opines that"Communities of practice $(\mathrm{CoP})$ are groups of people who share a concern or a passion for something they do and learn how to do it better as they interact regularly." Participatory Action Research (PAR) builds relations of personal trust to elicit fully and comprehensively the problems among the communities of practice $(\mathrm{CoP})$. It collates the goals, values and beliefs of the participants who have an interest in user experience and try to incorporate user experience in their development processes.Overall, PAR was used in this research. During the participation period, the researchers attempt to engage in communication to understand the problems within the CoP. The researchers then identify the actions to be performed in order to solve the problems found during the participatory session. The proposed framework in this study is based on the model by Jokela and Abrahamsson (2001) on the positive relationship between usability or user experience and the performance of UXD.This framework focuses on the practice to produce quality product through the current trend on UXD.

Revised Manuscript Received on June 22, 2019.

Idyawati Hussein, School of Computing, Universiti Utara Malaysia, 06010 UUM, Sintok, Malaysia

Azham Hussain, School of Computing, Universiti Utara Malaysia, 06010 UUM, Sintok, Malaysia

Emmanuel O.C. Mkpojiogu, School of Computing, Universiti Utara Malaysia, 06010 UUM, Sintok, Malaysia, Department of Computer and Information Technology, Veritas University, Abuja, Nigeria

ChenKim Lim, Faculty of Art, Computing \& Creative Industry, Sultan Idris Education University, 35900 TanjongMalim, Perak, Malaysia

KiamLam Tan, Faculty of Art, Computing \& Creative Industry, Sultan Idris Education University, 35900 TanjongMalim, Perak, Malaysia
In the case of less mature organisations or a lowawareness country such as Malaysia, additional issues need to be considered for assessing: (1) awareness; (2) attitude; (3) skills; (4) empowerment; and (5) resources (Kuutti et al., 1998). The aim of this study is to evaluate the implicit practice among the community who labeled themselves as UXD practitioners. The definition of implicit practice for this study is following Vashist et al. (2011).The first practice evaluation frameworks proposed as "mini-theories" may be more suitable for designers to view the user and the user's task (Hammond et al., 1983). However, this first study ignored the organisational context in which individual design decisions are made, notwithstanding the fact that organisational context is very important in shaping the behaviour of the designer (Crilly et al., 2008; Stolterman, 2008). Paulk's (2009) Capability Maturity Model Integration (CMMI) defines the software process as a set of activities, methods, practices and transformations that people use to develop and maintain software and its associated products. CMMI is a process-improvement approach that helps an organisation to improve its performance. However, even when the product is CMMI certified, problems related to end users were reported to be no different from those with non-CMMI certified products (Solemon et al., 2010).

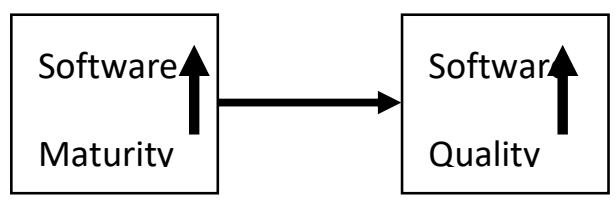

Fig.1Underlying principle behind $\mathrm{SEI}^{\mathrm{TM}}$

Figure 1 shows that the basic premise underlying the Software Engineering Institute's (SEI ${ }^{\mathrm{TM}}$ ) work on software maturity (CMMI) is that the quality of a software product is largely determined by the quality of the processes used to develop and maintain it (Paulk, 2009). At IBM, quality assessments based on 12 process stages, were characterised by 11 attributes measured on a five-point scale (Paulk, 2009). The 11 attributes were process, methods, adherence to practices, tools, change control, data gathering, data communication and use, goal setting, quality focus, customer focus, and technical awareness. The five-point scale consisted of traditionalism, awareness, knowledge, skill and wisdom, and an integrated management system. However, lessons learnt from these assessments were not formally published. 
In reality, the position of user centred design (UCD) in the organisations remains problematic (Mao et al., 2005; Jokela 2001; Gulliksen et al., 2003).According to Jokela (2001), when software-intensive systems and products in the market were examined, many of these systems represented poor levels of usability and UX (Hussain et al., 2016; 2017a; 2017b; 2017c; 2018). Jokela (2001) noted that in development organisations with high levels of usability capability, UCD is effective and efficient, resulting in usable products. A low usability capability level means either nonexistent or ineffective UCD, which results in products with poor usability.

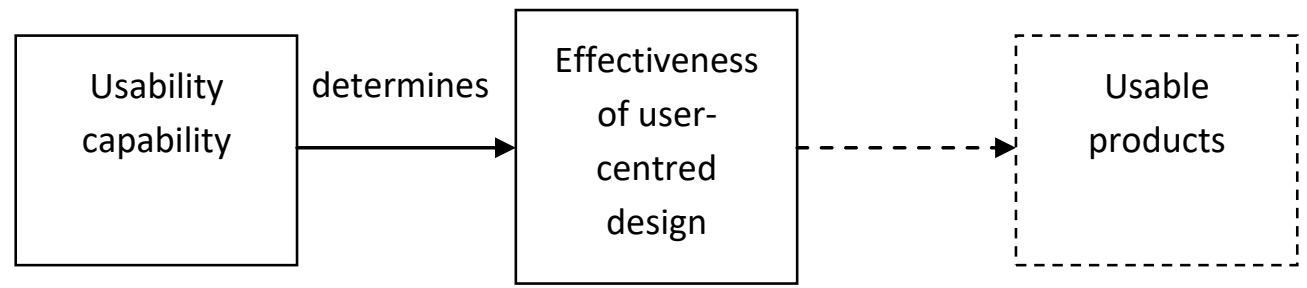

Fig. 2 Usability capability adapted from Kuuti et al., (1998)

Figure 2 identifies a usability capability model that guides usability capability assessment, focusing on the improvement actions that lead to improved usability capability (Kuuti et al., 1998). The assessment determines the ability of a development organisation to perform effective UCD and thereby to develop usable products.

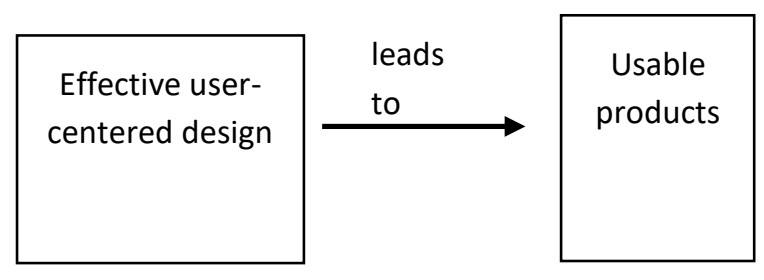

Fig. 3 Effect and cause of UCD
Figure 3 identifies an approach for interactive system development that focuses specifically on making systems usable, based on ISO 13407 (Jokela\&Abrahamsson, 2001). In the year 2000, managers in Japan translated the ISO 13407 standard into Japanese and it was applied in several organisations (Kurosu, 2011).Among the keys to successful system development is an increasing emphasis on defining appropriate HCI design processes and an integration of UCD processes with existing system and software development processes (Hefley et al., 1994).However, recent findings suggest that development actions or practices are shaped by decision makers external to UXD and Agile developers (Ferreira et al., 2010).One step towards identifying current practice is to carry out assessments to measure the state of UCD integration in organisation (Kuutti et al, 1998; Jokela et al., 2006).

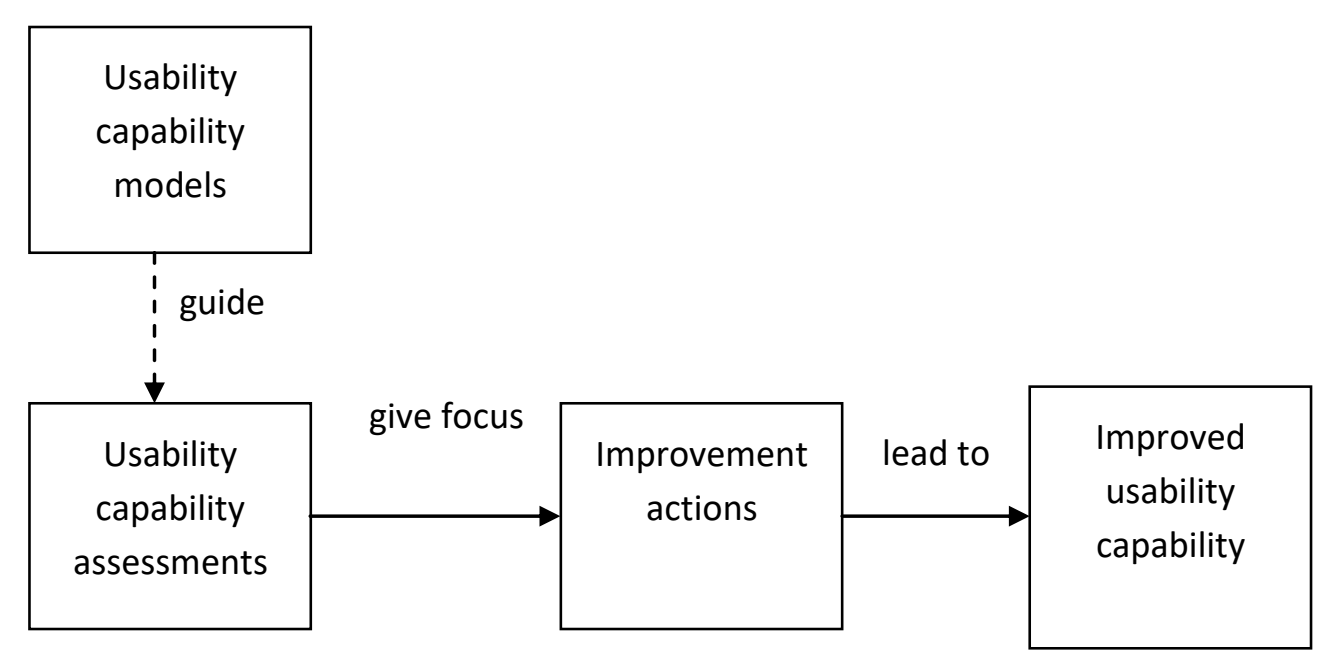

Fig.4 Usability capability model to assess an organisation's process for usability improvement (Jokela, 2000)

Figure 4 shows a usability capability model based on the CMMI's "best practice model". A poor (or lack of) communications strategy can create frustration due to the lack of clarity in roles and development, especially for the project team responsible for specific deliveries (Sandler, 2010).From the aspect of software, the Capability Maturity Model for Software (CMM or SW-CMM) is a reference model for appraising software process maturity; it is a normative model which helps software organisations progress along an evolutionary path from ad hoc, chaotic processes to mature, disciplined software processes 
(Herbsleb et al., 1997).In order to identify the state-of-theart of user experience practices, an assessment of the maturity of user experience should be conducted. Even though a draft of Usability/UX Maturity Model has been proposed (Marcus et al., 2009), there is insufficient information in the explanations of each level. Based on the draft provided to participants in a HCI-focused conference, UCD development is at its lowest (level 1) when UCD basic practices occur.

Venturi and Troost (2004) differentiate between $\mathrm{HCI} /$ usability companies and non-HCI companies by comparing usability as the core business or just one of the many business aspects. UCD integration is achieved when: (1) every phase of the product life cycle follows the principles of UCD; (2) the UCD team is provided with appropriate skills and experience; (3) UCD is supported by management commitment; (4) appropriate UCD infrastructure exists; (5) the awareness and culture of UCD are disseminated (Venturi \& Troost, 2004). Most maturity models are originated in quality management: Crosby's Quality Management Maturity Grid (QMMG) (Jokela et al., 2006). The lowest stage is the inability to recognise quality problems in the products-in-development. The management commitment is required in the enlightenment stage. Other models are described in the study, but few include the state of practice in HCI design in the processes that are being improved (Hefley et al., 1994). Among the models to improve the status of usability in software development projects is the Usability Leadership Maturity Model (ULMM). ULMM was developed by IBM between 1990 and 1992. There are three categories of assessment: (1) organisation; (2) skills; and (3) process. No information has been found about using this model, nor was it explained how to categorise each focus into the different levels of the maturity model.Several researchers are working towards institutionalising HCI in Asia and are building their work upon the Usability Maturity Model (Earthy, 1998; Joshi, 2004; Smith et al., 2007). However, these assessment frameworks may be too general for low awareness countries such as Malaysia, and too extensive for individual UXD practitioners who want to evaluate their own work practices
(Folstad et al., 2006).In the literature review, the draft of a Usability/User Experience Maturity Model proposed by Marcus (2009) and colleagues was found to be too general to the context of study in Malaysia. At level 1 of the framework, the initial user experience development maturity is characterised by basic user experience practices.However, the basic characteristics of experienced practices, and how to measure them, are not clearly stated. It is probable that the low understanding of the target populations of study of the terms and concept of user experience would lead to superficial results, as happened in a previous study (Dillon et al., 1993; Vukelja et al., 2007). This current study proposes a framework for the evaluation of UXD practice in industry.

\section{METHODOLOGY}

The main procedures for this study include identifying those practitioners who consider themselves responsible for user experience (UX) within an organisation or for a particular system or product, regardless of their title (Gulliksen et al., 2004). An online community is chosen as a starting point of the study. This is due to the result of preliminary study that shows that HCI conference participants and HCI students were not sufficient to become the subject of study (Idyawati et al, 2019a; 2019b).The CoP was identified through their participation in the online social media community namely Facebook and LinkedIn. The name of the group is identified as 'UX Malaysia' created by one of the Malaysian UX practitioner. 'UX Malaysia' is an official closed group of Facebook created in February 2012. This group have 1,178 members as in February 2015.In the real world, people will not automatically participate in online communities unless they share common interests and intended to interact with each other for a mutual benefit (Andrews, 2002). In fact, not all people are easily drawn to the virtual community unless the people have similar values. Hence, 'UX Malaysia' Facebook group represents some values of interest among the members for UX in Malaysia.The characteristics of a $\mathrm{CoP}$ are defined by the stages of CoP development in Table 1.

Table.1 Stages of development of a CoP

\begin{tabular}{|c|c|c|}
\hline $\begin{array}{c}\text { Stages of } \\
\text { Development }\end{array}$ & Characteristics & Activities \\
\hline Potential & People face similar situations & Searching for contacts of similar interests \\
\hline Coalescing & $\begin{array}{l}\text { Members come together to recognise } \\
\text { their potential }\end{array}$ & $\begin{array}{l}\text { Exploring connectedness, defining a joint enterprise, } \\
\text { negotiating a community }\end{array}$ \\
\hline Active & $\begin{array}{l}\text { Members engage in developing a } \\
\text { practice }\end{array}$ & $\begin{array}{l}\text { Engaging in joint activities, creating artefacts, } \\
\text { adapting to changing circumstances, renewing } \\
\text { interests, commitments, and relationships }\end{array}$ \\
\hline Disperse & $\begin{array}{l}\text { Members no longer engage very } \\
\text { intensely, but the community is still alive } \\
\text { as a force and centre of knowledge }\end{array}$ & $\begin{array}{l}\text { Staying in touch, communicating, holding reunions, } \\
\text { calling for advice }\end{array}$ \\
\hline Memorable & $\begin{array}{l}\text { The community is no longer central, but } \\
\text { people still remember it as a significant } \\
\text { part of their identity }\end{array}$ & $\begin{array}{l}\text { Telling stories, preserving artifacts, collecting } \\
\text { memorabilia }\end{array}$ \\
\hline
\end{tabular}


Table 1 identifies the characteristics of a community of practice's development, starting from the first stage until the community disperses. In this case, the researchers conducted a series of active and passive observations among UX Malaysia participants to find out if the characteristics of CoP exist within and between this group of participants. A CoP is not a community of interest, such as people who share particular hobbies. Members of a community of practice are practitioners who develop and share a repertoire of resources such as experience, stories, tools and ways of addressing recurring problems - in short, a shared practice. It takes time and interaction to develop a CoP. In order to investigate the stages of UX CoP development, the researchers chose to perform a participant observation method; characteristics such as what it is about and how it functions are identified in this stage. This method was chosen as a result of the operational definition of CoP, where membership is based on participation and being a volunteer. Overall, PAR and grounded theory was used to facilitate the framework proposed in this study. The PAR consisted of the triangulation of several methods such as netnography, survey, interview, observation, and focus group.

\section{RESULTS}

The result of this study is a framework of current-stateanalysis. In order to evaluate UX practice, a framework for current-state-analysis was refined to establish the assessment criteria. In contrast to existing models, this framework included knowledge, goals and values that determine the awareness of UXD. It is also able to measure the constraints according to the practitioners' circle of influence and circle of concern in the development environment. There were three areas to be identified in this framework: first, the people who have similar interests, concerns and passion about a domain; secondly, their explicit and implicit practice; and thirdly, the constraints or obstacles to practice, which might be (1) direct; (2) indirect; or (3) with no control (Covey, 1999, p.85). Figure 5 illustrates the current-state-analysis framework, which shows practice to optimise the impact of the UXD process based on the grounded data findings in this study. It can be used to evaluate both individual and group practitioners. For this framework, the community of practice was distinguished through the PAR approach. In Figure 5, the assessment of practice is divided into three main categories: (1) implicit practice, (2) explicit practice and (3) constraints. Implicit practice is categorised into two: (1) values and (2) goals while explicit practice comprises of job roles/design decision and knowledge. The framework evaluation is based on grounded theory.

Implicit Practice: Implicit practice includes cognition, emotion and the motivation of practitioners. Here, emotion is related to the passion to practise UX; cognition of the principles in practising UX; and motivation to the values of the practitioners. The following revised UCD principles are defined as "UXD principles". The finding in this study points to the importance of identifying the differences between UX practitioners and non-UX practitioners by their values and willingness to represent end users in the design process. This is in line with previous studies, which found that end users and their tasks were rarely gathered, due to the belief that end users did not know what they wanted in a product (Woolgar, 1994; Marti \& Bannon, 2009).Implicit practice isgrouped into values and goals.

Values: Values in this study have not much different with beliefs (Fishbein, 1963; Ford, 1992). The fundamental values of UXD practitioners should be related to an early focus on users and tasks, empirical measurement and iterative design. These were among the principles to be followed in order to practice UX (Gould \& Lewis, 1985, Bygstad et al., 2008; Marti \& Bannon, 2009). Contrary to the expectation, previous study found IT professionals' resistance to including users in the development process. This was due to the reigning culture in software development practice. In prior study, UX practitioners were keen to understand the user's perspectives and willing to perform iterations based on the end user feedback, not client who do not use the system at all. No matter which kind of development processes designers or developers used, the fundamental principle was willingness to change according to the feedback from end users. However, there were cases where developers rarely attended to user feedback or bug reports because the end users were perceived as lacking technical skills and command of language (Bach et al., 2009). It is more important to evaluate professionals who have an interest in UX than those who have no wish to include UX in the development process. Therefore, PAR was applied to identify these professionals, their implicit and explicit practices, as well as constraints that affected their practices. These findings were in line with Curtis et al. (1988) who found that software development projects were affected by corporate politics, culture and procedures. It was also identical with findings by Bekker and Vermeeren (1996), on insufficient resources which constitute time, money and equipment constraints. Here, one participant's company was identified as seeking guidance but being unwilling to accept the cost and schedule (Karat \& Dayton, 1995; Bygstad et al., 2008). 


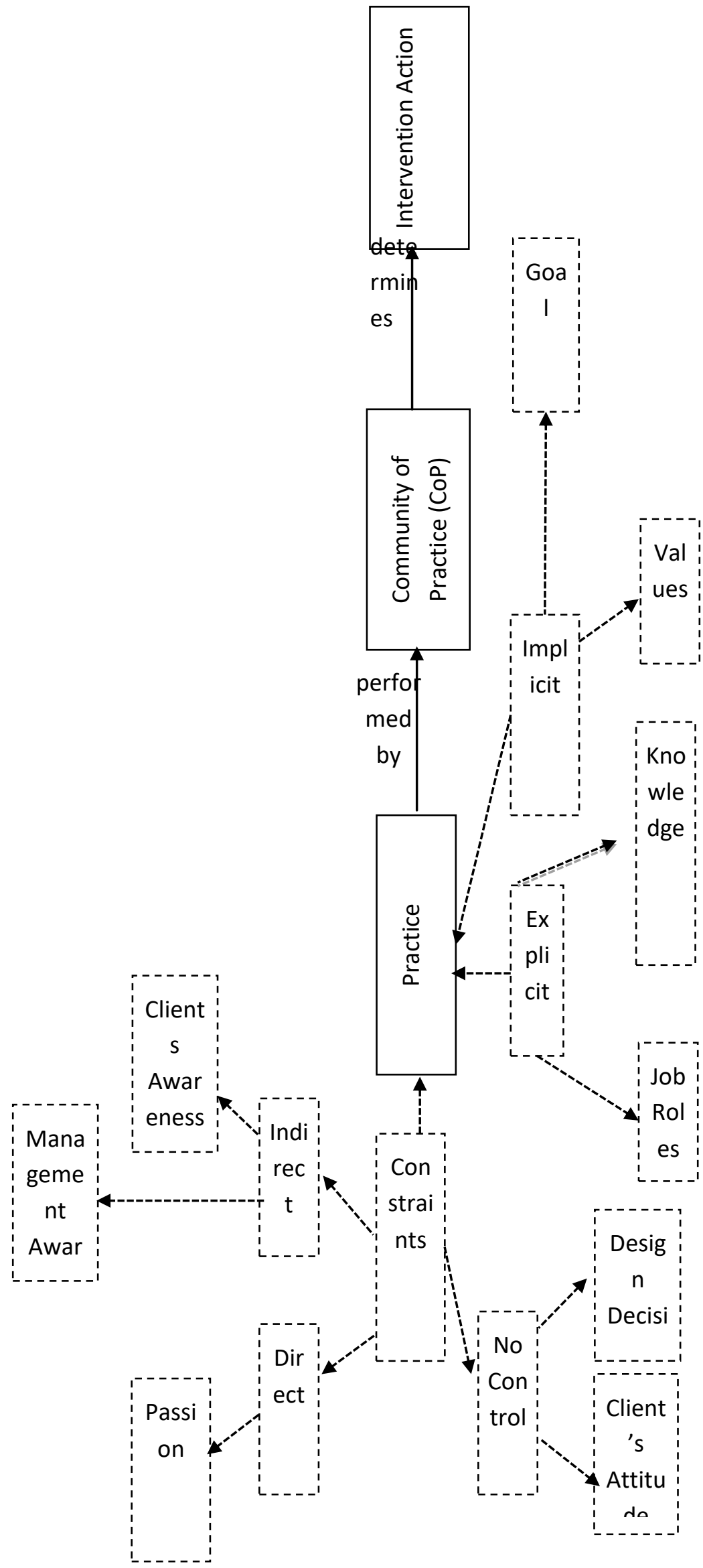

Fig. 5 Enhanced'current-state-analysis'framework 
Goal: In this evaluation framework, goal theory is applied, to assume that goals are cognitive representations of what practitioners are trying to accomplish. Goal theory is conscious and accessible to evaluation as it will influence motivation, affect, cognition and behaviour. Goal formulation in the framework is based on the context of use and activity, but according to the individual's subjective wellbeing (SWB), the characteristics of goals will influence the goal itself (Ehrlich, 2012). There are two dimensions to the goal: approach and avoidance (Pintrich, 2000). An approach goal is moving towards positive emotions while an avoidance goal is moving away by negative emotions (Pintrich, 2000; Ehrlich, 2012). However, one may question why people remain attached to goals that they see as being relatively unattainable (Hadley \& MacLeod, 2010). A possible answer lies in the concept of conditional goalsetting theory, which is based on a hierarchical model of goals with the most concrete at the bottom and the most abstract at the top (Carver \& Scheier, 1990; Hadley \& MacLeod, 2010).

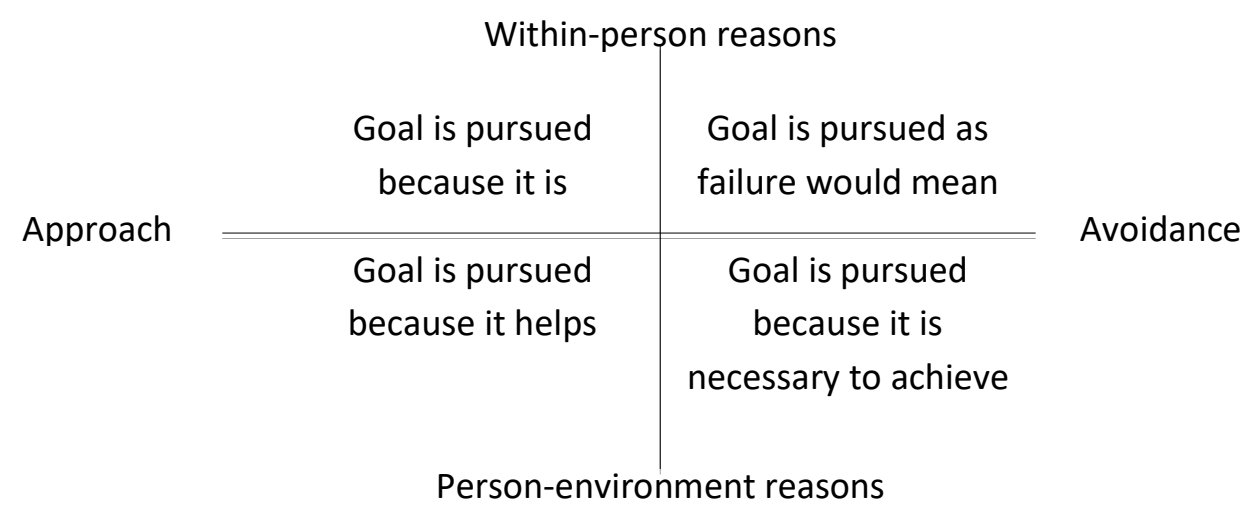

Fig. 6Goal-striving reasons adapted from Ehrlich (2012)

Figure 6 shows the distinction between within-person and person-environment goals where the categorisation is based on internal and external factors. Both within-person and person-environment can influence the SWB. The reasons for this could be explained by self-determination theory (SDT), which focuses on the social-contextual conditions that facilitate the natural processes of self-motivation and intention development (Ryan \& Deci, 2000). According to Pen Densham, "there are no perfect men in this world, only perfect intentions" (Ehrlich, 2012).In this PAR study, survey methods identified the second level of goals (Pintrich, 2000) concerning not only the CoP's general goals with regard to UX but also reasons "why" (Ford, 1992), participants were motivated to attend the meetings. Motivation is defined as the organised pattern of three psychological functions that serve to direct, energise and regulate goal-directed activities. Motivation includes personal goals, emotional arousal processes, and personal agency beliefs (Ford, 1992, p.3). The most interesting finding was that the UX definition rated by respondents in the survey showed a hierarchy of importance, as suggested in recent findings by Park et al. (2013). Other researchers agree on the importance of the goal, although it has received little attention in the Information Systems (IS) literature (Gasson, 2003).This may be because design practice can be spontaneous, without preparation, and exploiting changes offered by a general plan or moral principles (Gasson, 2003). However, goal is essential because it is what motivates the individual (Bandura, 1997). Motivation is categorised as both internally and externally driven. Design goals based on hedonomics theory can be used to explain achievement, motivation and behaviour.These findings have important implications for developing a hierarchical set of goals, by establishing the design goal, definitive objectives, the planning process and implementation. During the planning process, objectives will be transferred to become

measurements and design standards in a loose terminology of goals. The results suggested that the specific design goal may be different in different applications, such as informational websites, web apps, e-commerce websites and other online systems. In this study, the context of technology was not mentioned or highlighted, which influenced the level of design goals among the UX CoP. Critical applications such as e-commerce and surgical applications that require precision and a high-definition graphical user interface (Dillon et al., 1993) were not included during the survey. However, the upper level of rating, which is customisability and desirability, is similar to Hancock's (2005) theory.

Explicit Practice: It is encouraging to compare the results in this study with Vashist's (2011), who found that language, tools, documents, images, symbols, well-defined roles, codified procedures and regulations are among the various elements that makes practice explicit. The present findings are consistent with other research which found lack of knowledge as one of the obstacles impeding the practice of UX (Gulliksen et al., 2003; Vukelja et al., 2007; Zhou et al., 2008). In this study the language used in definitions of UX could determine the level of knowledge among practitioners. The terms UX and UXD were used frequently, but their definitions varied and denoted many different contexts and subject fields (Law et al., 2008; Sundbo \& Sorensen, 2013). Here, the use of a definition that includes a hierarchical level of design goal can be applied to measure knowledge.Although many researchers and practitioners agreed that UX includes all aspects of users' interaction; experience without a product or service should not be included as UX, and should be categorised as brand experience instead (Park et al., 2013). 
From the HCI perspective, UX evolved from classical usability to accommodate the fuzzy quality of hedonic attributes (Hassenzahl et al., 2006; Law et al., 2007, 2009; Adikari et al., 2013). A working definition of UX is required that matches the local environment in developing countries such as Malaysia. While Klang Valley is considered one of the more modern and high tech urban areas, with available Internet connectivity, there were still rural places in Malaysia suffering without electricity. Perhaps UX definitions in developing country should consider the hierarchical needs of users. Explicit practice comprises of job roles/design decision and knowledge.

Job Roles: During the observation session of the PAR, participants drew attention to a clear pattern of a job change and job-title transition in design. This suggests that professionals who envision a career shift are aware of potential changes to their career paths or job titles. In the focus group session, some participants expressed a lack of confidence in management understanding of UX roles. The job roles may have influence on the design decision such as being the manager of a team and leading a group of people in organisations. Recent research has found that different job titles have different empathy in user experience practice, especially with those who conduct user research and those who create products, e.g the designer role (Putnam \& Kolko, 2012). To relate the result with theory, psychological equation of behaviour states that it is a function of the person and their environment underlies behaviour of practicing (Lewin, 1945; Shoda, 2004).

$\mathrm{B}=f(\mathrm{P}, \mathrm{E})$

(where B - Behaviour; $f$ - Function; $\mathrm{P}$ - Person; E Environment)

Cognitive psychologists agree that a person's behaviour is influenced by the environment in which the person lives or works (Gould \& Lewis, 1985; Solso et al., 2005; Sternberg, 2009). It is difficult to identify the factors that most strongly influence a person's behaviour especially, when it involves the organisation's constraints and other external influences (Poltrock \&Grudin, 1994).However, this study did not investigate further in identifying practice differences between the designer, UX practitioner and management. Instead, the findings point to a huge gap between the role of the front-end designer and back-end developer, as observedin the in-situ interviews and observation sessions. Perhaps, the hierarchy status on the job roles may be able to influence the practice of UXD among individual team members.

Knowledge: Knowledge here is that of practitioners, management, end users and clients. The level can be evaluated by the source of knowledge, for example through formal education or conscious effort (Dayton et al., 1993). It is difficult to evaluate knowledge because it is not static and keeps changing as humans learn, forget and make mistakes (Turri, 2013).The survey session results show that many participants acquired on-the-job UX knowledge, suggesting a clear need for evaluating the knowledge of the people directly involved in a project, such as front-end designer, back-end developer, client and design decision maker. The present result suggests that practitioners should be evaluated according to what and how they know, as well as on their metacognitive knowledge, which concerns "awareness of" and "knowledge about" one's own cognition (Krathwohl, 2002).This dimension will reflect the order of importance and differences among individuals and team members. On the other hand, clients' knowledge will be evaluated using the classic 'to label' and 'identify knowledge classes'. Clients who lack knowledge tend to talk about colour tone and size of the button, and keep on changing their minds over several meetings. Clients who know what they want discuss flow and how information is displayed.

Measuring Constraints: Constraints encountered by individuals who are motivated to practise user experience in the development process were evaluated. The findings corroborate those of Covey (1999), but to his suggestion that the problems fall into one of three areas were added two more categories: (4) between no control and indirect control; and (5) between indirect and direct control.

Table. 2 Constraints or problems evaluation scale

\begin{tabular}{|l|l|l|l|l|l|}
\hline Scale & No Control & $\begin{array}{l}\text { Between No Control } \\
\text { and Indirect Control }\end{array}$ & $\begin{array}{l}\text { Indirect } \\
\text { Control }\end{array}$ & $\begin{array}{l}\text { Between Direct and } \\
\text { Indirect Control }\end{array}$ & $\begin{array}{l}\text { Direct } \\
\text { Control }\end{array}$ \\
\hline Net positive value (NPV) & -2 & -1 & 0 & 1 & 2 \\
\hline Likert & 1 & 2 & 3 & 4 & 5 \\
\hline
\end{tabular}

Table 2 illustrates this categorisation of five levels of constraint, which was incorporated in the evaluation framework and measured on Net Positive Value (NPV) and five-point Likertscales. It was expected that controlling influence would be increased if the empowerment or design decision making was higher. Therefore, the design decision making was positioned between constraints and practice.

Direct Control: Direct control constraints involve the individual's own attitude, passion and perceptions of UX. At this level, constraints can be reduced or solved by focusing on the individual level, reinforcing positive energy to change their own behaviour. Conscious effort to gain knowledge is one of the skills needed by the UCD practitioner (Dayton et al., 1993).
Between Direct Control and Indirect Control: Constraints related to team, project manager, senior member's knowledge and awareness of UX were considered as between direct and indirect control. For example, some participants were able to influence friends and colleagues to attend a second UX Malaysia meeting. This could be seen in the participant observation session, where some participants were from the same companies, or came at other people's invitation. 
Indirect Control: Indirect constraints include problems involving the behaviors of other people, such as management and clients' belief in UX. Here, problems can be solved by changing methods of influence, such as educating the management or client, as suggested by one netnography member. The result matches earlier studies suggesting that management support is important for UCD integration in an organisation (Karat \& Dayton, 1995; Bekker \& Vermeeren, 1996; Gulliksen et al., 1999).

Between Indirect Control and No Control: Prior studies have noted the importance of corporate politics, culture and procedures in influencing the incorporation of usability in a project (Curtis et al., 1988). Hence, projects should be aligned with the company goals; at the same time, effective communication is required inside and outside company ( $\mathrm{Yi}$ \& Yun, 2006).

No Control: No control constraints are related to problems that individuals can do nothing about, such as past or situational realities. In this study, clients' attitude was considered to be a no control constraint, unless the designer was given power to make design decisions. Netnography linked clients' attitude to a lacking of respect or trust towards designers. This result has not been described in any previous studies.

Design Decision: Some of the issues emerging from these findings are related to a design decision-making power in a project or team. Participants would be more likely to influence management and clients regarding UX if they had the authority to make design decisions. Further work is required to confirm this.In this evaluation framework, it is important to distinguish between three job roles in UX practice: (1) User Researcher; (2); Designer; (3) Management. Other recent research found that different UX roles exhibit different levels of empathy (Putnam \& Kolko, 2012; Clemmensen, 2013).

\section{CONCLUSION}

In this study, using PAR and grounded theory, an evaluation framework was developed to assess the UXD practice in industry. The study was conducted among a UXD community of practice. The proposed framework incorporated implicit, and explicit design practices as well as practice constraints.Implicit practice is grouped into values and goals while explicit practice comprises of job roles/design decision and knowledge.Constraints encountered by individuals who are motivated to practise user experience in the development process includes those related to: direct control, between direct control and indirect control, indirect control, between indirect control and no control and no control. This study fills a gap in the literature by providing an evaluation framework for understanding the current practice of UXD among individual practitioners or team-workers in order to effectively embrace user experience in the development process.

\section{REFERENCE}

1. Adikari, S., McDonald, C., \& Campbell, J. (2013). Reframed Contexts: Design Thinking for Agile User Experience Design. In A. Marcus (Ed.), Design, User Experience, and Usability. Design Philosophy, Methods, and Tools, Vol. 8012, Springer Berlin Heidelberg, 3 - 12.
2. Bach, P. M., DeLine, R., \& Carroll, J. M. (2009). Designers wanted: participation and the user experience in open source software development. Paper presented at the Proceedings of the 27th international conference on Human factors in computing systems, Boston, MA, USA.

3. Bandura, A. (1993). Perceived self-efficacy in cognitive development and functioning. Educational psychologist, 28(2), 117-148

4. Bygstad, B., Ghinea, G., \&Brevik, E. (2008). Software development methods and usability: Perspectives from a survey in the software industry in Norway. Interacting with Computers, 20(3), 375-385. doi: 10.1016/j.intcom.2007.12.001

5. Carver, C. S., \&Scheier, M. F. (1990). Origins and functions of positive and negative affect: a control-process view. Psychological review, 97(1), 19.

6. Clemmensen, T., Hertzum, M., Yang, J., \& Chen, Y. (2013). Do Usability Professionals Think about User Experience in the Same Way as Users and Developers Do? In P. Kotzé, G. Marsden, G. Lindgaard, J. Wesson \& M. Winckler (Eds.), Human-Computer Interaction INTERACT 2013, Vol. 8118, Springer Berlin Heidelberg, 461-478.

7. Covey, S. R. (1999). The 7 habits of highly effective people: Restoring the character ethic. London: Pocket Books.

8. Crilly, N., Good, D., Matravers, D., \& Clarkson, P. J. (2008). Design as communication: exploring the validity and utility of relating intention to interpretation. Design Studies, 29, 425-457. doi: 10.1016/j.destud.2008.05.002

9. Curtis, B., Krasner, H., \&Iscoe, N. (1988). A field study of the software design process for large systems. Communication of the ACM, 31(11), 1268-1287.

10. Dayton, T. (1993). Skills needed by user-centered design practitioners in real software development environments: report on the $\mathrm{CHI} 92$ workshop. SIGCHI Bull., 25(3), 16-31. doi: 10.1145/155786.155790

11. Dillon, A., Sweney, M., \& Maguire, M. (1993). A survey of usability evaluation practices and requirements in the European IT industry. Paper presented at the HCI'93, Cambridge.

12. Earthy, J. (1998). Usability maturity model: Human centeredness scale (pp. 34): Lloyd's Register and the European Commision 1998.

13. Ehrlich, C. (2012). Be careful what you wish for but also why you wish for it - goal-striving reasons ans subjective well-being. The Journal of Positive Psychology, 7(6), 493-503.

14. Fishbein, M. (1963). An investigation of the relationship between beliefs about an object and the attitude toward that object. Human relations.

15. Ferreira, J., Sharp, H., Robinson, H., Sillitti, A., Martin, A., Wang, X., \& Whitworth, E. (2010). Values and Assumptions Shaping Agile Development and User Experience Design in Practice. Agile Processes in Software Engineering and Extreme Programming. In W. Aalst, J. Mylopoulos, M. Rosemann, M. J. Shaw \& C. Szyperski (Eds.), Springer Berlin Heidelberg, Vol. 48, 178-183.

16. Folstad, A., Bark, I., \&Gulliksen, J. (2006). How HCI-practitioners want to evaluate their own practice. Paper presented at the Proceedings of the 4th Nordic conference on Human-computer interaction: changing roles, Oslo, Norway.

17. Ford, M.E. (1992). Motivating Humans: Goals, Emotions and Personal Agency Beliefs: Sage Publications, Inc.

18. Gould, J.D., \& Lewis, C. (1985). Designing for usability: Key principles and what designers think. Communications of the ACM, 28, 300-311.

19. Gulliksen, J., Lants, A., \&Boivie, I. (1999). User centered design Problems and possibilities. A summary of the 1998 PDC \& CSCW workshop, SIGCHI Bulletin, Seattle, USA, 2-31.

20. Gulliksen, J., \& Lantz, A. (2001). Design versus design-from the shaping of product to the creation of user experiences.

21. Hadley, S. A., \& MacLeod, A. K. (2010). Conditional goal-setting, personal goals and hopelessness about future. Cognition and Emotion, 24(7), 1191-1198.

22. Hammond, N., Jorgensen, A. , MacLean, A. , Barnard, P., \& Long, J. (1983). Design practice and interface usability: Evidence from interviews with designers. Paper presented at the Proceedings of the SIGCHI conference on Human Factors in Computing Systems, Boston, Massachusetts, United States.

23. Hancock, P. A., Pepe, A. A., \& Murphy, L. L. (2005). Hedonomics: the power of positive and pleasurable ergonomics. Ergonomics Design, 13(1), 8-14. 
24. Hassenzahl, M., Law, E. L-C., \&Hvannberg, E. T. (2006). User experience - Towards a unified view. Paper presented at the UX WS NordiCHI'06: COST294-MAUSE, Oslo Norway.

25. Hefley, W.E., Buie, E.A., Lynch, G.F., Muller, M.J., Hoecker, D.G., Carter, J., \& Roth, J. T. (1994). Integrating human factors with software engineering practices. Paper presented at the Human Factors and Ergonomics Society Annual Meetings 1983-1994.

26. Herbsleb, J., Zubrow, D., Goldenson, D., Hayes, H., \&Paulk, M. (1997). Software quality and the capability maturity model. Commun ACM, 40(6), 30-40. doi: 10.1145/255656.255692

27. Hussain, A., Abdullah,A., Husni, H., \&Mkpojiogu, E.O.C. (2016). Interaction Design Principles for Edutainment Systems: Enhancing the Communication Skills of Children with Autism Spectrum Disorders. Rev. Tec. Ing. Univ. Zulia. 39(8), 45-50. doi: 10.21311/001.39.8.06

28. Hussain, A., AbdRazak, M.N.F., Mkpojiogu, E.O.C. \&Hamdi, M.M.F (2017). UX evaluation of a video streaming application with teenage users. Journal of Telecommunication, Electronic \& Computer Engineering (JTEC), 9 (2-11), 129-131

29. Hussain, A., Isam, M., \&Mkpojiogu, E.O.C. (2017). A UX assessment of a mobile recommender app for household electrical energy savings. Journal of Telecommunication, Electronic \& Computer Engineering, 9 $(2-11)$

30. Hussain, A., Mkpojiogu, E.O.C., Musa, J., \&Mortada, S. (2017). A user experience evaluation of amazon kindle mobile application. Proceedings of the 2nd International Conference on Applied Science and Technology (ICAST'17), Kedah, Malaysia. AIP Conference Proceedings 1891 (1), 020060

31. Hussain, A., Mkpojiogu, E.O.C., Musa, J., Mortada, S., \&Yue, W.S (2018). Mobile Experience Evaluation of an e-Reader App. Journal of Telecommunication, Electronic \& Computer Engineering (JTEC) 10(1-10), 11-15.

32. Idyawati, H., Hussain, A. \&Mkpojiogu, E.O.C. (2019a). The knowledge of human-computer interaction (hci) and user experience design (uxd) in malaysia: an analysis of the characteristics of an hcifocused conference

33. Idyawati, H., Hussain, A. \&Mkpojiogu, E.O.C. (2019b). The state of user experience design practice in malaysia: an exploratory study

34. Jokela, T., \&Abrahamsson, P. (2001). Modelling usability capabilityIntroducing the dimension. Lecture Notes in Computer Science, 1-16.

35. Jokela, T., Siponen, M., Hirasawa, N., \& Earthy, J. (2006). A survey of usability capability maturity models: Implications for practice and research. Behaviour \& Information Technology, 25(3), 263 - 282.

36. Joshi, A. (2004). Institutionalizing HCI - the challenges in India. White Paper.

37. Karat, J., \& Dayton, T. (1995). Practical education for improving software usability. Paper presented at the $\mathrm{CHI} 95$.

38. Krathwohl, D. R. (2002). A revision of Bloom's taxonomy: An overview. Theory into practice, 41(4), 212-218.

39. Kurosu, M. (2011). Usability in Japan. In I. Douglas \& Z. Liu (Eds.), Global Usability. London: Springer-Verlag.

40. Kuutti, K., Jokela, T., Nieminen, M., \&Jokela, P. (1998). Assessing human-centred design processes in product development by using the INUSE maturity model.

41. Law, E.L.C., Vermeeren, A.P.O.S., Hassenzahl, M., \& Blythe, M (2007). Towards a UX manifesto. Paper presented at the BCS HCI Group Conference, Lancaster University, UK.

42. Law, E. L.-C., Hvannberg, E. T., \&Cockton, G. (2008a). A Green Paper on Usability Maturation Maturing Usability (pp. 381-424) Springer London

43. Law, E. L.-C., Roto, V., Hassenzahl, M., Vermeeren, A., \&Kort, J. (2009). Understanding, scoping and defining user experience: A survey approach. Paper presented at the CHI 2009, Boston, USA

44. Lewin, K. (1945). Social Conflicts: Selected Papers on Group Dynamics. London: A Harper International edition.

45. Mao, J-Y., Vredenburg, K., Smith, P. W., \& Carey, T. (2005). The state of user-centered design practice. Commun. ACM, 48(3), 105-109. doi $10.1145 / 1047671.1047677$

46. Marcus, A., Gunther, R., \&Sieffert, R (2009). Validating a Standardized usability/user-experience maturity model: A progres report. Paper presented at the HCII 2009.

47. Marti, P. \&Bannon, L. (2009). Exploring User-Centred Design in Practice: Some Caveats. Knowledge, Technology and Policy, 22(1), 7 15. doi: 10.1007/s12130-009-9062-3

48. Park, J., Han, S. H., Kim, H. K., Cho, Y. \& Park, W. (2013) Developing elements of user experience for mobile phones and services: survey, interview, and observation approaches. Human
Factors and Ergonomics in Manufacturing \& Services Industries, 23(4), 279-293.

49. Paulk, M.C. (2009). A history of the capability maturity model for software. The Software Quality Profile, 1(1)

50. Pintrich, P. R. (2000). An achievement goal theory perspective on issues in motivation terminology, theory, and research. Comtemporary Educational Psychology, 25, 92-104.

51. Poltrock, S. E., \&Grudin, J. (1994). Organizational obstacles to interface design and development: two participant-observer studies. ACM Transactions on Computer-Human Interaction (TOCHI), 1(1), $52-80$

52. Putnam, C., \&Kolko, B. (2012). HCI professions: differences \& definitions. In CHI'12 Extended Abstracts on Human Factors in Computing Systems (pp. 2021-2026). ACM.

53. Ryan, R. M., \&Deci, E. L. (2000). Self-determination theory and the facilitation of intrinsic motivation, social development, and well-being. American Psychologist, 55(1), 68-78.

54. Sandler, D. (2010). Best practices for applying Agile techniques to data warehouses. Business Intelligence Journal, 15(4), 17-27.

55. Shoda, Y. (2004). Individual differences in social psychology: Understanding situations to understand people, understanding people to understand situations: Sage.

56. Smith, A., Joshi, A., Liu, Z., Bannon, L., Gulliksen, J., \& Li, C. (2007). Institutionalizing HCI in Asia. Paper presented at the INTERACT 2007, Rio de Janeiro, Brasil.

57. Solemon, B., Sahibuddin, S., \&Ghani, A.A. (2010). Adoption of requirements engineering practices in Malaysian software development companies. ASEA 2010, CCIS, 117, 141-150.

58. Solso, R. L., MacLin, M. K., \&MacLin, O. H. (2005). Thinking Concept formation, logic, and decision making Cognitive Psychology (pp. 417-450): Pearson Allyn and Bacon

59. Sternberg, R. J. (2009). Cognitive psychology (Fifth ed.). Wadsworth, USA: Wadsworth, Cengage Learning.

60. Stolterman, E. (2008). The Nature of Design Practice and Implications for Interaction Design Research. International Journal of Design, 2(1), $55-65$

61. Sundbo, J., \& Sorensen, F. (2013). Handbook on the Experience Economy: Edward Elgar Publishing

62. Turri, J. (2013). Unreliable knowledge. Philosophy and Phenomenological Research.

63. Vashist, R., McKay, J., \& Marshall, P. (2011). Reflecting on use of practice theories to understand 'practices': A boundary practice perspective on work of business analysts. Paper presented at the International Workshop on Practice Research, Helsinki.

64. Venturi, G., \&Troost, J. (2004). Survey on the UCD integration in the industry. Paper presented at the NordiCHI'04, Tampere, Finland.

65. Vukelja, L., Muller, L., \&Opwis, K. (2007). Are Engineers Condemned to Design? A Survey on Software Engineering and UI Design in Switzerland. Paper presented at the INTERACT 2007.

66. Wenger, E., Trayner, B., \&Laat, d. M. (2011). Promoting and assessing value creation in communities and networks: a conceptual framework. Netherlands: Dutch Ministry of Education, Culture and Science.

67. Woolgar, S. (1994). Rethinking requirements analysis: some implications of recent research into producer-consumer relationships in IT development. Paper presented at the Requirements engineering.

68. Zhao, F., Collier, A., \& Deng, H. (2014). A multidimensional and integrative approach to study global digital divide and e-government development. Information Technology \& People, 27(1), 38-62. 